\title{
TECNOCIÊNCIA, INDUSTRIALIZAÇÃO E PESQUISA NA FINANCEIRIZAÇÃO RADICAL DO CAPITALISMO E DA EDUCAÇÃO SUPERIOR
}

\author{
JoÃo dos ReIS SiLVA JúNIOR \\ Everton Henrique Eleutério FargonI \\ Universidade Federal de São Carlos (UFSCar), São Carlos, São Paulo, \\ Brasil
}

\begin{abstract}
Resumo: O objetivo deste artigo consiste na problematização do processo de globalização, de mercantilização da universidade estatal brasileira no contexto que tende de forma acentuada a transformar a universidade, retirando-lhe a crítica e reduzindo a ciência à tecnociência, colocando-a como parte da economia mundial, fundindo ainda mais o capital financeiro ao industrial. Busca-se compreender este evento como parte do processo de financeirização do capitalismo que culminou na desvalorização do valor-trabalho.
\end{abstract}

Palavras-Chave: Educação Superior. Industrialização. Ciência. Pesquisa. Tecnociência.

INTRODUÇÃO

O presente artigo busca refletir acerca da mediação da tecnologia na sociedade contemporânea e como o conhecimento produzido na educação superior, no amplo contexto de globalização, está reduzindo a ciência à tecnociência. Para tanto, serão discutidos alguns conceitos, tais como o conhecimento matéria-prima, conhecimento mercadoria e industrialização - situando, portanto, o horizonte da educação superior no núcleo da união dos mercados de diferentes países.

As transformações societais que permearam o mundo nos últimos decênios do século XX e nos primeiros decênios do século XXI foram caracterizadas por diferentes conjunturas políticas pelos seis continentes, porém, tais diferenças baseiam-se principalmente em contextos culturais e históricos, enquanto que em nível planetário as semelhanças aparecem na forma econômica, posto que nações que outrora situavam-se na periferia do capitalismo mundial, como Singapura, ao final da segunda década do novo milênio destacam-se no campo econômico como grandes potências em razão de estratégias que avançaram a industrialização do país junto com o investimento massivo em pesquisa.

O exemplo de Singapura repete-se em muitos outros países onde o conhecimento científico, apoiado por governos que realizaram e realizam altos investimentos na educação superior, é parte crucial da estratégia econômica nacional que 
busca o desenvolvimento nos mais diversos setores que compõem a sociedade civil. Em outras palavras, no cenário globalizado, entre mercados e corridas tecnológicas, os países que mais prosperaram economicamente foram os que também mais investiram em pesquisa, inovação e tecnologia.

Neste processo, de táticas econômicas e inovações científicas, ocorreu o estreitamento da ciência e tecnologia, fusão que vem modificando a atividade científica concentrando-a na produção de conhecimento para inovação tecnológica, isto é, a laboração da pesquisa e o trabalho técnico em ciência estão se reorganizando em função da competição econômica mundializada sob a hegemonia plena do capital financeiro. Neste quadro, de vinculação entre tecnologia e ciência, a tecnociência predomina e orienta-se sob a ótica do mercado produtivo, estabelecendo a remodelação da produção científica para a sociedade, em que a ciência como descoberta com tempo próprio e não imposto, movida pela dúvida e pela busca, trouxe mudanças estruturais na educação superior e, especialmente, para o trabalho do professor-pesquisador.

\title{
A REDUÇÃO DA CIÊNCIA EM TECNOCIÊNCIA
}

O conceito de tecnociência é passível de muitas interpretações. Geralmente o termo aparece empregado no esclarecimento de questões do campo tecnológico ou, pormenorizadamente, na informática. Mas a ideia de tecnociência está muito além da forma simplificada da amálgama tecnologia mais ciência.

Para a Filósofa Madel Luz (2014), a ciência busca recriar a natureza à sua imagem e, por meio da tarefa de transformar o mundo, o pressuposto primário das tecnologias com a ciência baseia-se em fornecer soluções individuais e societais ao mesmo tempo em que produzem extensões inovadoras para a vida humana. Luz (2014) complementa:

\begin{abstract}
A tecnociência é a marca epistêmica típica do modo específico de pensar e ser da sociedade capitalista ocidental, originada pela ciência moderna dos fins do século XVI [...] esta episteme tem, portanto, cinco séculos, sendo jovem diante de saberes e modos de produção de verdades de outras culturas e civilizações, mesmo ocidentais. A eficácia e a utilidade social são atualmente seus parâmetros básicos para aferição de veracidade, e não mais a comprovação de verdades teóricas (LUZ, 2014, p. 5, grifo nosso).
\end{abstract}

Todavia, tecnologias ajudaram a reorganizar e progredir sociedades. Invenções se aperfeiçoaram, como máquinas para tratamentos clínicos, meios de locomoção mais evoluídos, sistemas de comunicação, entre outros. Porém, no âmbito de produção de ciência, a indústria mundial, em parceria com intelectuais acadêmicos, passou a criar novas demandas, quer dizer, a produção industrial se renovou não só para atender exigências e necessidades, mas modificou-se para gerar novos desejos de consumo, desejos que Marx (2010, p. 80) chamou de "valorização do mundo das coisas" ao dizer que o sujeito está posto sob a reprodução social fetichizada pelo consumo. 
Essas mudanças parecem guardar proximidades com a era do capitalismo industrial e representam na contemporaneidade o que Marx pensava no século XIX sobre a relação social-capital, e que se intensificou e se metamorfoseou, posto que há 200 anos eram criadas mais tecnologias para aumentar a rentabilidade da produção industrial, e no século XXI o quadro tecnológico mundial fragmentou-se e os pesquisadores trabalham para criar tecnologias que atendam o comércio de novos produtos. O capital industrial amalgamado com o capital financeiro permanece como uma das maiores potências indutoras de inovação, porém sob novas perspectivas. Na medida em que as tecnologias avançam e novos produtos são criados, todo o processo se repete adequado a projetos estratégicos, visando especialmente ao lucro financeiro mais do que ao operacional. Há, nesse processo, a desvalorização pelo capitalismo do valor-trabalho. Daí derivariam todas as reformas que se realizam no Brasil, sem resistência alguma, desde 2016. Nesse contexto, a tecnociência é utilizada como instrumento de produção de valor, numa vertiginosa velocidade de produção que pode romper com barreiras éticas e morais (CARVALHO, 2000; SANTOS, 2003).

No campo científico acadêmico, singularmente na educação superior, na qual se realiza a formação de novos cientistas, os professores-pesquisadores vivenciam na contemporaneidade o que Luz (2014) denominou de "marca epistêmica" da sociedade capitalista ocidental. Trabalham sob a lógica do mercado, incorporados na educação superior globalizada, sem fronteiras, com concorrência e metas. Esse fato contribui e culminou no predomínio das tecnociências sobre as ciências, originando o que Slaughter e Rhoades (2009) chamam de raw material knowledge, que, segundo Silva Júnior (2017, p. 65), significa "conhecimento matéria-prima", ou seja, é o uso do conhecimento científico humano como input de novos produtos tecnocientíficos no capitalismo acadêmico global e a nova divisão internacional do trabalho acadêmico científico.

Jasanoff (2003), ao citar Vannevar Bush,' salienta este aspecto da tecnociência contemporânea ao dizer que a regulação tecnocientífica predomina sobre as políticas de educação superior e do trabalho, visto que todos estão reunidos num "contrato social para a ciência". Por exemplo, Jasanoff (2003, p. 13), ao mencionar que a National Science Foundation, dos Estados Unidos, garante recursos estatais e autonomia para a ciência "em troca de descobertas, inovações tecnológicas e recursos humanos treinados", reconhece que as formas de capacitação e financiamento do trabalho de pesquisadores nas universidades os afiguram como peças de um engenhoso mecanismo de produção.

Esta dicotomia de contribuição societal por meio das criações tecnocientíficas e uso da tecnociência como dispositivo de ganhos está constituindo uma nova concepção de ciência, sua ressignificação ou desaparecimento. Como caso análogo, os investimentos em grande parte nas áreas consideradas de ponta e em setores estratégicos para o desenvolvimento de um país têm fins bélicos, pauta que põe em dúvida o avanço da tecnociência em razão de representar uma condição de vitória na corrida militar (ECHEVERRÍA, 2003).

Entretanto, outro aspecto interessante de se notar na composição da tecnociência - acentuada no século XXI - é o seu determinismo. Conforme Feenberg (1991), este conceito refere-se a uma visão recorrente nas ciências sociais desde Marx e estabelece que o desenvolvimento tecnológico é a força motriz do fluxo histórico, interpretação proveniente de ampla compreensão científica dos processos tecnológicos. 
Isto é, seja no plano bélico, industrial, econômico ou social, o determinismo tecnocientífico cruza fronteiras e institui a tecnologia como invariável determinante no progresso universal.

De modo geral, essa concepção determinista de tecnociência corresponde ao silogismo de que a tecnologia não é mais humanamente controlada; a humanidade passou a ser controlada pela tecnologia e, mais do que isso, o modus vivendi do homem reconfigurou-se por meio de quesitos de eficiência. Nesse sentido, à medida que as tecnologias - derivadas das tecnociências - evoluem, as sociedades se modificam e as instituições mudam.

Ademais, a universidade como lócus de ensino, pesquisa e inovação, além de desempenhar papel crucial no campo científico, é polo propulsor crítico e de progresso societal, corroborando na mentalidade analítica humana dentro da sociedade civil enquanto se tornam os pilares epistemológicos da esfera científica. Isso faz com que os pesquisadores e agências que fomentam a tecnociência comercializem ainda mais conhecimentos.

Celso Furtado, na década de 1960, destacava esta racionalidade econômica por meio da industrialização como forma de superação do subdesenvolvimento latinoamericano e, com amparo do Estado, tal modelo em múltiplas dimensões, como aumento de investimento em pesquisas nas universidades, fortaleceria a indústria brasileira diante da concorrência internacional. Na defesa do projeto industrializante, Furtado $(1961$, p. 91) afirma que "o desenvolvimento econômico [...] consiste na introdução de novas combinações de fatores de produção que tendem a aumentar a produtividade do trabalho".

Os novos fatores de produção mais regulares são originários das produções tecnocientíficas do século XXI e estão amalgamados na combinação das pesquisas realizadas nas instituições acadêmicas em parcerias com grandes corporações ou no fracionamento em spin-offs; logo, os setores dinâmicos que aumentam a produtividade e, consequentemente, a produção nacional, encontram-se vinculados às atividades industriais, que dependem de novas e constantes atualizações tecnológicas. Por isso, o subdesenvolvimento presente no trabalho das nações de "terceiro mundo" fica explícito pelo "empréstimo da tecnologia" e não por meio da "criação de tecnologia":

Podemos definir uma estrutura subdesenvolvida como aquela em que a plena utilização do capital disponível não é suficiente para a completa absorção da força de trabalho, ao nível de produtividade correspondente à tecnologia que prevalece no setor dinâmico do sistema. É a heterogeneidade tecnológica entre setores ou departamentos de uma mesma economia que caracteriza o subdesenvolvimento (FURTADO, 1961, p. 195).

Na narrativa de Furtado (1961), a tecnociência não foi expressa no contexto de industrialização para evolução econômica por meio do elo entre universidade, indústria e tecnologia, mas, próximo aos 60 anos da publicação do seu livro Desenvolvimento e Subdesenvolvimento, o raciocínio que Furtado outrora apresentou tornou-se imperante na conjuntura global econômica, e os países que criaram projetos nacionais de 
desenvolvimento com base no investimento massivo em educação básica, educação superior, ciência e tecnologia com foco na industrialização avançaram nas mais variadas categorias e rankings, enquanto a tecnociência, juntamente a esse movimento econômico, predominou.

\section{A PRODUÇÃO DE CONHECIMENTO ORIENTADA POR ESTRATÉGIAS POLITICAS E ECONÔMICAS}

A multiterritorialidade da tecnociência é a alusão pedagógica da onipresença da tecnologia no planeta Terra; satélites registram ações de povos aborígenes, operações militares são realizadas a milhares de quilômetros da base de comando, alterações climáticas são tecnologicamente previstas meses ou anos antes de acontecer. Os exemplos são inúmeros, os pontos de vista também, uma vez que produções da tecnociência podem resolver problemas coletivos e, do mesmo modo, podem agravar. É um dúbio conceito que faz as pessoas não escaparem à vigilância da tecnologia, ora pela conectividade que consolida George Orwell como um adivinho pelo seu "Grande Irmão", ora pela possibilidade de reduzir distâncias na comunicação entre as pessoas, basta ver o avanço das chamadas de vídeo em alta definição buscando fazer o mesmo que ocorre no cenário de ficção científica que outrora, como em Blade Runner, parecia ser um futuro distante.

Um ponto em comum de todo esse conjunto tecnocientífico é a universidade, principalmente as que possuem centros de pesquisa. A título de exemplo, no Brasil as instituições estaduais e federais públicas de ensino superior são lócus de alto nível de produção de conhecimento que, segundo dados do relatório Research in Brazil - A report for CAPES (2017), da empresa estadunidense Clarivate Analytics, as universidades públicas brasileiras são responsáveis por mais de $95 \%$ da ciência no Brasil. Além disso, no Censo da Educação Superior do mesmo ano foi divulgado que o Brasil possuía 2.448 instituições de educação superior (IES), sendo 2.152 instituições privadas e 296 públicas, ou seja, apenas $12 \%$ das IES produzem conhecimento.

A combinação dessas informações com a conjuntura global integralizada pela tecnociência evidencia a lógica das novas configurações de produção no capitalismo mundial. Por um lado, existe o mercado de ensino superior, fato evidente no Brasil em razão de $88 \%$ das instituições de ensino superior serem empresas privadas; por outro, as universidades estatais brasileiras compõem a demanda crescente de formação de profissionais que estejam intimamente relacionadas com todo o mercado científico. Isso significa que professores-pesquisadores das IES estatais utilizam do conhecimento científico como matéria-prima em pesquisas enquanto formam os "novos cientistas", que desenvolvem habilidades e competências próprias do âmbito dos negócios.

Kuhn (1978) principiou questões que explicitam como a compreensão teórica sobre a comunidade científica funciona diante das mudanças econômicas no mundo. $O$ consenso e a ciência como produto de convenção são, por exemplo, indispensáveis na nova economia mundial. Contudo, a comunidade científica detém o monopólio da prática científica, pois é a unidade que produz conhecimento e é legitimadora do conhecimento científico. Tal fato no processo de aproximação entre as diversas sociedades e nações, muito praticado pelas universidades, corresponde à razão do avanço da tecnociência mundialmente, seja no âmbito econômico, social, político e, inclusive, cultural, dado que a proeminência em destaque na globalização da educação superior está na integração de 
mercados existentes entre os países.

No Brasil, as semelhanças com a forma de produção de conhecimento que vem se desenhando mundialmente tem início durante a Reforma do Aparelho do Estado em 1995 (SILVA JÚNIOR; SGUISSARDI, 2001). Neste contexto, de abastecimento do mercado tecnológico global e de submissão a grandes corporações, as universidades brasileiras, face à mundialização econômica, passam por constantes intentos políticos de privatização, especialmente da pesquisa. Circunstância que está causando a diáspora de intelectuais acadêmicos para o mercado e pode isolar ainda mais as ciências humanas, ${ }^{2}$ criticada por ser ideológica, política e de não produzir mais-valia nas cadeias mundiais de valor.

Entretanto, diferente do Brasil, governantes de muitos países entenderam que no cenário de mercado globalizado amparado pelo consumo, especialmente de novas tecnologias, a aproximação da indústria com a universidade é uma das soluções econômicas mais promissoras e, sobretudo, com massivo financiamento estatal.

Respeitando as ciências humanas como polo de produção crítica que requer também investimento, o governo alemão anunciou em 2019 que mais de 42 milhões de euros seriam carreados para as suas universidades. O maior percentual está destinado para pesquisa, tecnologia e extensão com foco na indústria nacional, verba que a longo prazo possibilitará a contratação de mais professores e ampliação dos campi em todo território; campi que estão em avançado estado de internacionalização e acompanham a decisão do Estado na gratuidade de todo o ensino superior no país.

Ao estabelecer conexão de realidade acadêmica entre Brasil-Alemanha, não podemos ignorar o fato das diferenças históricas, como exemplo, colônia e colonizador, mas na interpretação global e, mais recentemente, do Capítulo III da Constituição Federal de 1988, na exigência da apreciação da educação como direito social em todas as etapas e níveis, não há especificações. Isto é, não há no documento alíneas sobre políticas de financiamento à pesquisa (BRASIL, 1988).

Mas, se há o ônus de que a produção científica brasileira se concentra quase sua totalidade nos $12 \%$ em universidades públicas, qual a razão da constante investida (ou ameaça) de privatização das IES?

Em 2019, um dos maiores desalinhos políticos sobre a universidade pública brasileira foi em seu papel na economia do país, enquanto - socialmente - a insciência sobre as atividades de trabalho nas universidades estatais ganhou repercussão principalmente por meio de políticos no uso do poder simbólico e imperativo nas redes sociais (oriundas da tecnociência) ao deturparem a grande potência de produção de conhecimento das universidades públicas, invertendo em muitos casos a competência científica das instituições.

Maurício Tragtenberg, na década de 1970, já alertava sobre o perigo de reduzir as universidades aos interesses econômicos hegemônicos. Em contrapartida, depois de 2016, o longevo "aviso" de Tragtenberg perdeu-se na avalanche de desinformações, principalmente nas mídias sociais. $E$, ao refletir a realidade acadêmica brasileira pósreforma do Estado com o alerta de Tragtenberg, nota-se, por exemplo, com o texto do Programa FUTURE-SE, ${ }^{3}$ o objetivo claro de uma autonomia acadêmica ressignificada ou, ainda, empresariada, inspirada no modelo norte-americano de universidade. 
Neste contexto, de reformas gerencialistas, de privatização crescente e de ajustes estatais em prol de uma nova ordem global, intensificado a partir da metade dos anos 1990, o estado brasileiro não conseguiu obter vantagens com as potencialidades da tecnociência combinada aos centros de pesquisa acadêmicos. As ideias, por exemplo, de um plano nacional de desenvolvimento foram e estão sendo obliteradas por interesses políticos e econômicos que brecam o emprego de alto capital público na educação superior.

\section{UNIVERSIDADE PÚBLICA, TECNOCIÊNCIA E INDUSTRIALIZAÇÃO}

Embora o número de startups no Brasil, segundo levantamento feito pela Associação Brasileira de Startups (ABStartups), tenha ultrapassado o número de 12 mil unidades em 2019, uma aterradora estatística assombra o Brasil e expõe a dificuldade política e econômica do país em avançar industrialmente. Segundo estudos e dados da Confederação Nacional do Comércio de Bens, Serviços e Turismo (CNC), entre os anos de 2015 e 2019 a recessão econômica fez o Brasil fechar 17 fábricas por dia. Ao todo são 25.376 indústrias a menos comparadas a dezembro de 2014, o que eleva o alerta sobre o crescimento da desindustrialização brasileira.

Essa sinalização estatística sustenta-se por fatores que intercorrem em diversos âmbitos e épocas. A industrialização, exemplarmente, é pauta política antiga no Brasil; apesar disso, o presente diagnóstico mostra que uma das chaves para o desenvolvimento de um país está reduzindo em vez de ajudar seu desenvolvimento. Isto é, expõe-se desta maneira o embrião da mercantilização da política no capitalismo, em que países periféricos recebem filiais de grandes corporações para produção com mão de obra barata enquanto na periferia econômica o impulso econômico se reprime.

Brito Cruz (2000, p. 25) afirmava que o grande desafio em pesquisa e desenvolvimento no Brasil era criar um ambiente que estimulasse empresas ao investimento no conhecimento para aumentar sua competitividade. Duas décadas depois, a forma burocrática da política e a dimensão ideológica do capitalismo fez com que o Brasil tivesse apenas alguns espasmos de altos investimentos, vide o recorde de financiamento de pesquisas em P\&D e C\&T entre os anos 2012 e 2014 que, em parceria de empresas, despontaria a ciência acadêmica brasileira como dispositivo de avanço econômico.

Como consequência desse contexto, verifica-se o aporte representativo de investimento em $P \& D$ e C\&T na medida em que possibilita dar aporte à transformação do conhecimento incorporado pelas empresas em seu rol de produtos, melhor dizendo, o propósito é satisfazer as necessidades dos clientes atuais ou gerar novas necessidades (MORT, 2001). A indústria nacional e, consequentemente, a universidade produtora de pesquisas e inovação participam como coadjuvantes ou na adjacência no processo de desenvolvimento e fabricação de novos produtos nacionais.

Em 2010, o relatório de Produção Tecnológica Global divulgado pela Organização das Nações Unidas (ONU), na Conferência das Nações Unidas sobre Comércio e Desenvolvimento, revelou que o Brasil gastou US\$ 16 bilhões a mais do que vende em tecnologia. $O$ estudo apresentou também que a acelerada industrialização de países de mercado emergente contribuiu na redução da pobreza, efeito que não se realizou no Brasil, posto que a diminuição dos níveis de pobreza na conjuntura brasileira foi 
determinada principalmente por programas sociais acentuados nos primeiros governos petistas. Ainda segundo a ONU, em 2009 o Brasil importou US\$ 20 bilhões em aparelhos tecnológicos à medida que exportou apenas US\$ 3,6 bilhões.

Considerando as condições mercantis, os governos brasileiros pós-impeachment de Dilma Rousseff em vez de racionalizarem a corrida tecnológica mundial como chance de colocar o Brasil na competição do mercado global, prática que possibilitaria à nação novamente despontar economicamente, estreitaram ainda mais o pensamento sobre inovação e tecnologia nas grandes corporações do capitalismo mundial. A industrialização nacional, mesmo em pauta, se perde no polo antiético da reestruturação produtiva por meio da naturalização do fundo público por parte do capital, demandando novas reformas, como a Lei № 13.467, de 13 de julho de 2017, conhecida como a Reforma Trabalhista e a Emenda Constitucional 103, oriunda da Proposta de Emenda à Constituição $6 / 19$ e a Reforma da Previdência.

Essas reformas consistem em um amplo acordo que extrapola o campo político e alicerçam a desindustrialização nacional por diferentes meios. Por exemplo, ramificações da tecnociência como a robótica, base fundamental na produção de tecnologias de ponta, quando apensadas e desenvolvidas por meio dos trabalhos realizados nos centros de pesquisa acadêmicos, podem prover a indústria nacional com soluções mercadológicas, mas o fenomênico sucateamento das universidades públicas que está em processo desde 1995 ganhou consistência em 2019 com o corte orçamentário de 42\% em ciência e tecnologia. $O$ "apagão" na ciência brasileira que aumentara o debate da racionalização social e econômica da educação superior, na qual o intento dominante e respaldado pelo texto do Programa FUTURE-SE, agora como projeto de Lei, consolida a "americanizaçãomundialização" da universidade pública brasileira nos últimos patamares da divisão internacional do trabalho (SILVA JÚNIOR, 2017).

Nesta conjuntura do não entendimento (ou disfarce) do estado brasileiro sobre as potencialidades da produção de conhecimento e investimento em ciência de base em todas as áreas do conhecimento afasta a indústria nacional da emergência de novas tecnologias que vem permitindo a proliferação de novas subjetividades, isto é, muitas ressignificações sobre a percepção do universo social e reordenamentos da vida pósmoderna estão causando profundas implicações culturais e sociopolíticas. Nessa lógica, o estado brasileiro, que lentamente adentra nas mudanças mercantis globalizadas com base na tecnociência, encontra-se no segundo plano na condição que Latour (2000) e Haraway (2013) chamam de hibridismo resultante da interação homem e máquina, nas quais as relações sociais no século XXI são decorrentes do novo contexto tecno-científico.

No entanto, talvez resida numa melhor leitura de globalização pelo estado brasileiro para que, contraditoriamente, identifique na avariada educação superior pública notáveis soluções para o país, posto que, se 15 universidades públicas produzem mais de $60 \%$ da ciência brasileira, ${ }^{4}$ a margem de possibilidades de desenvolvimento econômico considerando o estágio atual do capitalismo é relativamente alta, pois mesmo com as indústrias e também a universidade sendo ordenadas sob a mundialização do regime de predominância financeira, a nova racionalidade acadêmica sendo produtora de conhecimento tecno-científico elevará as condições de concorrência se apensadas como apoio fulcral na constituição de novas indústrias do Brasil. 
Restringindo exemplos, podem ser incorporadas referências de outras nações e aprimoradas na forma de planejamento a fim de prevenir erros e mirar nos acertos. Dois modelos, ambos internacionalizados, dentre muitos que poderíamos citar, correspondem a exitosos processos de industrialização que, dispostos em situações históricas diferentes, obtêm falhas e sucessos. No primeiro caso, Estados Unidos, país soberano do capitalismo mundial e detentor de empresas cujas marcas lideram o mercado da tecnociência, apodera-se do conhecimento produzido nos centros de pesquisas das universidades e alterou qualitativamente o trabalho do professor pesquisador ao transformar a forma de seu trabalho em imaterial, superqualificado e produtivo. Ademais, como grave consequência de uma universidade mundializada focada no mercado científico:

\begin{abstract}
Os estudantes e recém-formados nas universidades dos Estados Unidos passam por um transtorno que está afetando bruscamente na economia do País [...] a dívida do financiamento dos cursos de graduação e Pós-graduação das universidades norte-americanas está em 1,5 trilhão de dólares, valor que superou em junho de 2019 a dívida total do cartão de crédito nos EUA. Esta realidade que formou e está formando uma geração de jovens endividados tornou-se pauta da corrida eleitoral estadunidense de 2020 e, mesmo assim, as universidades permanecem na condição de universidades-empresas cobrando altos valores dos cidadãos com foco na produção de conhecimento mercadoria (SILVA JÚNIOR; FARGONI, 2019, p. 47).
\end{abstract}

O segundo caso bem-sucedido e que afortunou o país essencialmente em industrialização é o de Singapura. O caso chinês também é de relevância global, porém, a ex-colônia britânica, que décadas antes do fim do século XX encontrava-se na periferia do capitalismo mundial, pôs em prática o plano que Brito Cruz busca para o Brasil desde a década de 1990. Segundo dados da revista inglesa Times Higher Education, Singapura subiu nos principais rankings de educação superior e, entre 2016 e 2020, terá investido mais de US\$ 14 bilhões apenas em pesquisa e desenvolvimento, investimento alinhado com a criação de novas indústrias nacionais que colocou 80 delas entre as cem maiores empresas de tecnologia do mundo.

Em 2019, o governo de Singapura anunciou a abertura de 10 mil novos empregos voltados para área de tecnologia a serem preenchidos até 2021, vagas que abrangem diversas áreas do conhecimento, de ciências exatas a humanas; empregos para linguistas, pedagogos, psicólogos, engenheiros, desenvolvedores de softwares e produtos, administradores, entre outros. Essa frente de progresso por meio da economia digital tem como protagonismo a Agência para Ciências, Tecnologia e Pesquisa ( $A *$ Star), órgão de fomento a pesquisa que funciona especialmente na busca de resultados que descubram novas aplicações comerciais. Criada em 2002, a agência de fomento estatal financiou mais de 2 mil projetos de pesquisa com empresas de todo o mundo com foco na criação de novas indústrias nacionais. Após auxiliar na formação de novos 1,5 mil Ph.Ds, recebeu em 2018 o prêmio de quinto órgão público mais inovador em pesquisa pública pela agência britânica Reuters.

A tecnociência de Singapura não é somente exemplo na industrialização da nação e de excelência em educação superior pública. O plano nacional de desenvolvimento que vem sendo executado desde os últimos decênios do século XX 
mostra como acertos políticos, sem negar as humanidades e a educação básica num contexto mundializado de expansão neoliberal, corrobora para o progresso societal do país. E mesmo com a base econômica das teses da social-democracia e do Estado de bemestar social, de acordo com a Teoria Geral de Keynes, com o início do seu declínio na década de 1970, Singapura, muito por meio da arrecadação dos rendimentos advindos da indústria nacional, desenvolveu-se amplamente no âmbito científico $e_{\text {, }}$ consequentemente, na educação básica a superior no século XX. Como exemplo, no Programa Internacional de Avaliação de Alunos (PISA) de 2018, em estudo realizado pela Organização para a Cooperação e Desenvolvimento Econômico (OCDE), que avalia a qualidade educacional dos estudantes na faixa dos 15 anos, Singapura liderou todas as categorias, das ciências exatas e humanas, superando os tradicionais países escandinavos.

\section{CONSIDERAÇÕES FINAIS}

Retornando a Marx, as mudanças das esferas pública e privada mantêm relações entre si, sob mediações acentuadas no ciclo de movimentação do capital. $O$ valor produzido no âmbito da produção é potência, tendo potencial de se realizar ou não na esfera da circulação de mercadorias, isto é, a demanda do capital sempre foi diferente da demanda da classe trabalhadora, e no século XXI a tecnociência disparou como força de demanda com aplicativos e produtos novos todos os dias. Segundo Marx (1988), os meios de produção são o foco que, por meio do trabalho alienado, a reprodução do capital e das contradições da sociedade capitalista provocariam crises cíclicas de superprodução, fato corrente e, sobretudo, muito problemático para a sociedade capitalista contemporânea ao desequilibrar produções, gerando altos estoques, inflação, dívida interna e, sobretudo, por desvalorizar o valor-trabalho.

Nota-se que ao adotar os conceitos marxistas, a presente financeirização da economia mundial reproduz impasses centenários, porém, a busca por soluções e, pormenorizadamente, de inovação por meio de pesquisas ao usar do conhecimento científico de pesquisadores como matéria-prima mostra que o intelecto humano é produto, logo cabe aos Estados usarem beneficamente ou não, como forma de equilíbrio econômico e de modo consequente, social. O caso brasileiro com o filtro referencial estadunidense e similar ao de Singapura reflete o antigo paradigma e já histórico na sociedade contemporânea em que projetos nacionais de desenvolvimento ao serem executados respeitando pilares nacionais, como a educação básica e educação superior, contribuem diretamente na organização societal e, sobretudo, de progresso econômico, posto que pesquisa, tecnologia e inovação são eixos fundamentais da economia.

Enfim, é também de suma importância notar que ciência e tecnologia se tornaram inerentes às sociedades industriais, vínculo que resultou na concepção de tecnociência como caracterizadora da estreita relação da ciência e tecnologia e o modo como as pesquisas propendem cada vez mais às oportunidades tecnológicas mais do que aos interesses teóricos. Portanto, a tecnociência expressa os rumos, os novos paradigmas e a complexidade do tipo de pesquisa no profuso mercado científico global que conectou as relações científicas, a tecnologia e a indústria com a política. 


\section{TECHNOCIENCE, INDUSTRIALIZATION AND RESEARCH IN THE RADICAL FINANCIALIZATION OF CAPITALISM AND HIGHER EDUCATION}

ABSTRACT: The objective of this article is to problematize the process of globalization, of commodification of the Brazilian state university in the context that tends to transform the university, removing criticism, and reducing Science to technoscience, placing it as part of the world economy. We seek to understand this event as part of the financialization process of capitalism that culminated in the devaluation of the value of labor.

KEYWORDS: Higher Education. Industrialization. Science. Research. Technoscience.

\section{TECNOLOGÍA, INDUSTRIALIZACIÓN E INVESTIGACIÓN EN LA FINANCIALIZACIÓN RADICAL DEL CAPITALISMO Y LA EDUCACIÓN SUPERIOR}

RESUMEN: El objetivo de este artículo es problematizar el proceso de globalización, de mercantilización de la universidad estatal brasileña en el contexto que tiende a transformar a la universidad, eliminando sus críticas y reduciendo la ciencia a la tecnociencia, ubicándola como parte de la economía mundial. Buscamos entender este evento como parte del proceso de financiarización del capitalismo que culminó con la devaluación del valor del trabajo.

PALABRAS CLAVE: Educación Superior. Industrializacion. Ciencia. Investigación. Tecnociencia.

\section{NOTAS}

1) Cientista e político estadunidense; teve papel político importante no desenvolvimento da bomba atômica e pela ideia do memex (um dos primeiros computadores), precursor do conceito world wide web (www).

2) “Presidente da Academia Brasileira de Ciências (ABC), o físico Luiz Davidovich tem assinado cada vez mais cartas de recomendação para pesquisadores que deixam o Brasil [...] doutores não querem salários altos. Procuram, na verdade, insumos e equipamentos para os quais o governo brasileiro tem empenhado cada vez menos recursos nos últimos anos. O êxodo de cientistas, para Davidovich, é a ferida mais exposta do sistema de ciência e tecnologia (C\&T) do país, que se agravou no governo Jair Bolsonaro e seus contingenciamentos, ausência de projeto tecnológico e negação da ciência". VASCONCELOS, G. Valor Econômico. Fuga de cérebros é realidade, diz chefe da Academia Brasileira de Ciências. Rio de Janeiro. Disponível em: https:/valor.globo.com/brasil/noticia/2019/08/13/fuga-de-cerebros-e-realidade-diz-chefe-daacademia-brasileira-de-ciencias.ghtml Acesso em: 13 jan. 2020.

3) Programa Institutos e Universidades Empreendedoras e Inovadoras - FUTURE-SE. Disponível em: https://ufrj.br/sites/default/files/img-noticia/2019/07/projeto_de_lei_do_programa_futurese.pdf Acesso em: 13 jan. 2020. 
4) Relatório fonte - Research in Brazil: Funding Excellence (2019): Levantamento feito em parceria da Coordenação de Aperfeiçoamento de Pessoal de Nível Superior (CAPES) e a empresa Clarivate Analytics entre 2013 e 2018.

\section{REFERÊNCIAS}

BRASIL. Constituição da República Federativa do Brasil de 1988. Brasília: Senado Federal, 1988.

BRITO CRUZ, C. H. A Universidade, a Empresa e a Pesquisa que o país precisa. Revista Humanidades, Brasília, v. 45, n. 1, p.15-29, 2000.

CARVAlHO, E. A. Tecnociência e complexidade da vida. São Paulo em Perspectiva, v. 3, n. 14, p. 26-31, 2000.

ECHEVERRÍA, J. La revolución tecnocientífica. Madrid: Fondo de Cultura Económica de España, 2003.

FEENBERG, A. A Critical theory of technology. New York: Oxford University Press, 1991.

FURTADO, C. Desenvolvimento e subdesenvolvimento. Rio de Janeiro: Fundo de Cultura, 1961.

HARAWAY, D. Manifesto Ciborgue. In: HARAWAY, D.; TADEU, Tomaz (org.). Antropologia do ciborgue. As vertigens do pós-humano. Belo Horizonte: Autêntica, 2013. p. 33-118.

JASANOFF, S. Technologies of Humility: Citizen Participation in Governing Science. Minerva, v. 41, n. 3, p. 223-244, 2003.

KUHN, T. S. A estrutura das revoluções científicas. 2. ed. São Paulo: Perspectiva, 1978. LATOUR, B. Ciência em ação. São Paulo: UNESP, 2000.

LUZ, M. T. Impactos da tecnociência nos saberes, na cultura da vida e saúde. In: Fórum Sociológico, Série II, Circulação de saberes e desafios em saúde, 24., 2014, Lisboa. Anais [...]. Lisboa: NOVA, 2014. p. 27-32.

MARX, K. O Capital: Crítica da Economia Política. São Paulo: Nova Cultural, 1988.

MARX, K. Manuscritos econômico-filosóficos. Tradução, apresentação e notas Jesus Ranieri. 4. reimp. São Paulo: Boitempo, 2010.

MORT, J. Nature, value and pursuit of reliable corporate knowledge. Journal of Knowledge Management, Reino Unido, v. 5, n. 3, p. 222-230, 2001. 
SILVA JÚNIOR, J. dos R.; FARGONI, E. H. E.

SANTOS, L. Politizar as novas tecnologias: o impacto sócio-técnico da informação digital e genética. São Paulo: Ed. 34, 2003.

SILVA JÚNIOR, J. R; SGUISSARDI, V. Novas faces da educação superior no Brasil. 2. ed. São Paulo: Cortez Editora, 2001.

SILVA JÚNIOR, J. R. The new Brazilian University: a busca por resultados comercializáveis: para quem? 1. ed. Bauru: Canal 6, 2017.

SILVA JÚNIOR, J. R; FARGONI, E. H. E. Mundialização da educação superior: notas sobre economia, produção de conhecimento e impactos na sociedade civil. Trabalho \& Educação, Belo Horizonte, v. 28, n. 3, p. 35-49, set-dez, 2019.

SLAUGHTER, S; RHOADES, G. Academic capitalism and the new economy:

market, State and Higher Education. Baltimore, MD: Johns Hopkins University Press, 2009.

TRAGTENBERG, M. Sobre Educação, Política e Sindicalismo. São Paulo: Editores Associados; Cortez, 1990.

João dOS ReIS SILVA JúnIOR: Professor Titular da Universidade Federal de São Carlos, coordenador adjunto do projeto de pesquisa da Rede Universitas/Br, pesquisador convidado - Mercer University (GA-US) e Professor Visitante na condição de Full Professor na Arizona State University (2014-2015). Atualmente é membro do Comitê assessoramento de Educação do CNPq.

Orcid: https://orcid.org/0000-0003-2667-0371

E-mail: joaodosreissilvajr@gmail.com

Everton Henrique Eleutério Fargoni: Mestrado em Educação pelo Programa de PósGraduação em Educação (PPGE) da Universidade Federal de São Carlos (UFSCar). Graduado em Pedasogia pela UFSCar atualmente integra o Grupo de Estudos e Pesquisa de Economia Política da Educação e Formação Humana (GEPEFH) e é membro pesquisador do eixo de pesquisa 'Produção do Conhecimento' da Rede Universitas/BR.

Orcid: https://orcid.org/0000-0001-7536-9126

E-mail: evertonfargoni@gmail.com

Este periódico utiliza a licença Creative Commons Attribution 3.0, para periódicos de acesso aberto (Open Archives Iniciative - OAI). 